\title{
Homocysteine is a bystander for ST- segment elevation myocardial infarction: a case-control study
}

\author{
Ching-Yu Julius Chen ${ }^{1,2}$, Tzu-Ching Yang ${ }^{3}$, Christopher Chang ${ }^{4}$, Shao-Chun Lu ${ }^{3}$ and Po-Yuan Chang ${ }^{1,2^{*}}$ (D)
}

\begin{abstract}
Background: Homocysteine has been long considered a risk factor for atherosclerosis. However, cardiovascular events cannot be reduced through homocysteine lowering by B vitamin supplements. Although several association studies have reported an elevation of serum homocysteine levels in cardiovascular diseases, the relationship of homocysteine with ST-segment elevation myocardial infarction (STEMI) is not well established.

Methods: We prospectively enrolled STEMI patients who were consecutively admitted to an intensive care unit following coronary intervention in a single medical center in Taiwan. Control subjects were individuals who presented to the outpatient or emergency department with acute chest pain but subsequently revealed patent coronary arteries by coronary arteriography. The association between serum homocysteine levels and STEMI was investigated. A culture system using human coronary artery endothelial cells was also established to examine the toxic effects of homocysteine at the cellular level.
\end{abstract}

Results: Patients with chest pain were divided into two groups. The STEMI group included 56 patients who underwent a primary percutaneous coronary intervention. The control group included 17 subjects with patent coronary arteries. There was no difference in serum homocysteine levels ( $8.4 \pm 2.2 \mathrm{vs} .7 .6 \pm 1.9 \mu \mathrm{mol} / \mathrm{L}, p=0.142)$. When stratifying STEMI patients by the Killip classification into higher (Killip III-IV) and lower (Killip I-II) grades, CRP (3.3 \pm 4.1 vs. $1.4 \pm 2.3 \mathrm{mg} / \mathrm{L}, p=0.032)$, peak creatine kinase (3796 \pm 2163 vs. $2305 \pm 1822 \mathrm{IU} / \mathrm{L}, p=0.023)$, and SYNTAX scores $(20.4 \pm$ 11.1 vs. $14.8 \pm 7.6, p=0.033$ ) were significantly higher in the higher grades, while serum homocysteine levels were similar. Homocysteine was not correlated with WBCs, CRP, or the SYNTAX score in STEMI patients. In a culture system, homocysteine at even a supraphysiological level of $100 \mu \mathrm{mol} / \mathrm{L}$ did not reduce the cell viability of human coronary artery endothelial cells.

Conclusions: Homocysteine was not elevated in STEMI patients regardless of Killip severity, suggesting that homocysteine is a bystander instead of a causative factor of STEMI. Our study therefore supports the current notion that homocysteine-lowering strategies are not essential in preventing cardiovascular disease.

Keywords: Coronary artery disease, C-reactive protein (CRP), Homocysteine, ST-segment elevation myocardial infarction (STEMI), White blood cell (WBC)

\footnotetext{
* Correspondence: pychang@ntu.edu.tw

${ }^{1}$ Cardiovascular Center and Division of Cardiology, Department of Internal Medicine, National Taiwan University Hospital, 7 Chung-Shan South Road, 100 Taipei, Taiwan

${ }^{2}$ Division of Cardiology, Department of Internal Medicine, National Taiwan University College of Medicine, No.1, Ren-Ai Road Section 1, 100 Taipei,

Taiwan

Full list of author information is available at the end of the article
} 


\section{Background}

Homocysteine is a highly reactive, sulfur-containing amino acid formed as a byproduct of the metabolism of the essential amino acid methionine [1], and methylenetetrahydrofolatereductase (MTHFR) is a key enzyme in this process. The serum level of homocysteine is significantly elevated in areas with dietary folate and B vitamin deficiencies as well as in subjects with the MTHFR 677 TT genotype [2], which can be lowered by $\mathrm{B}$ vitamins, including folic acid, B6, and B12. Homocysteine used to be considered a risk factor for atherosclerosis, which was primarily observed in children with extremely elevated serum homocysteine levels as well as premature atherothrombotic disease, and basic studies demonstrated that homocysteine can induce vascular damage by promoting platelet activation, oxidative stress, endothelial dysfunction, hypercoagulability, vascular smooth muscle cell proliferation, and endoplasmic reticulum stress $[1,3,4]$. A meta-analysis that collected large numbers of prospective studies and corrected for a regression dilution bias did show a significant association between the serum level and the incidence of cardiovascular disease (CVD) [5-10]. Serum levels were also correlated with long-term outcomes in patients with documented coronary artery disease (CAD) or acute coronary syndrome [11, 12]. However, recent studies disclosed that even though serum homocysteine levels were reduced by $B$ vitamins in patients with stable CAD, acute coronary syndrome, or stroke, the rate of major adverse cardiac events was not reduced [13-17]. Moreover, there was no difference in early and late cardiovascular mortality among the tertiles of serum homocysteine levels in patients with ST-segment elevation myocardial infarction (STEMI) or non-ST-segment elevation acute coronary syndrome [18]. A possible explanation is the generally accepted concept of primary percutaneous coronary intervention (PCI) in STEMI, the common use of a new generation of drug-eluting stents in this era, $[19,20]$ and the development of a newer P2Y12 inhibitor, [21, 22] which has contributed to great improvements in survival and stent patency, thereby attenuating any potential benefits of homocysteine-lowering interventions. We tried to clarify the role of homocysteine in STEMI, an extreme entity of acute coronary syndrome, by making comparisons with subjects presenting with chest pain but proven to have patent or non-significant coronary arteries.

\section{Methods}

\section{Study population}

This study was approved by the institutional review board and conformed with the principles outlined in the Declaration of Helsinki. We prospectively enrolled STEMI patients who were consecutively admitted to an intensive care unit following coronary intervention in this study. The control group included individuals who presented to the outpatient or emergency department with acute chest pain but subsequently revealed patent coronary arteries by coronary arteriography. This study was carried out in a single medical center in Taiwan from March to September in 2014. STEMI was defined according to the 2013 American Heart Association (AHA)/American College of Cardiology (ACC) and European Society of Cardiology (ESC) guidelines, including persistent electrocardiographic (ECG) ST elevation and subsequent release of biomarkers of myocardial necrosis [23, 24]. All participants provided written informed consent.

\section{Study protocol}

We recorded the time elapsed from exhibition of symptoms to receipt of medical services and the door-toballoon time; demographic data and atherosclerotic risk factors including hypertension, diabetes, dyslipidemia, cigarette smoking, a family history of premature myocardial infarction, peripheral arterial disease, stroke, and the body-mass index; serum homocysteine, complete lipid profiles, hemoglobin A1c, white cell counts, C-reactive protein $(\mathrm{CRP})$, peak creatine kinase $(\mathrm{CK})$, and the time elapsed to the peak value; the severity of STEMI by the Killip classification and coronary anatomy by the SYNTAX score; life-threatening conditions including ventricular tachyarrhythmias, cardiac arrest, the use of an intra-aortic balloon pump (IABP) or extracorporeal membranous oxygenation (ECMO); echocardiographic parameters including the left ventricular ejection fraction (LVEF) and E/E'; electrocardiographic parameters including the PR and QTc interval, QRS duration, existence of fragmented QRS or early repolarization; and medications for acute coronary syndrome including antiplatelets, glycoprotein IIb/IIIa inhibitor, beta-blockade, angiotensin-converting enzyme inhibitor (ACEi) or angiotensin-II receptor blocker, statins, or antiarrhythmic drugs. We compared differences between the STEMI and control groups and analyzed whether there was a correlation between the severity of STEMI and the abovementioned parameters. All live STEMI patients were followed up for at least 1 month to evaluate their short-term prognosis.

\section{Cell cultures}

Human coronary artery endothelial cells (ECs; HCAECs, Clonetics, US), at passages 4 to 7 , were maintained in EGM-MV medium supplemented with $20 \%$ fetal bovine serum (FBS) and antibiotics. For the experiments, all cultures of subconfluent HCAECs were incubated with phosphate-buffered saline (PBS, as a control), homocysteine, cysteine, or electronegative L5 low-density 
lipoprotein (LDL) isolated from STEMI patients according to a previously described protocol $[25,26]$.

Cell viability 3-(4,5-dimethylthiazol-2-yl)-2,5-diphenyltetrazolium bromide (MTT) assay.

The chemical MTT was purchased from Sigma (St. Louis, MO) [26, 27]. HCAECs $\left(5 \times 10^{4}\right.$ cells/well $)$ were dispensed into 24-well plates and incubated for $24 \mathrm{~h}$ after the addition of homocysteine or different treatments, and the index of EC viability was determined by the colorimetric MTT (tetrazolium) assay. The absorbance was measured at a wavelength of $540 \mathrm{~nm}$ for viable cells using a microplate reader (Thermo Electron, Waltham, MA).

\section{Statistical analyses}

A Chi-squared or Fisher exact test was used to compare categorical variables. Continuous variables were determined by either Student's $t$-test or a one-way analysis of variance (ANOVA). All continuous data are expressed as means \pm standard deviation. A two-tailed $p$ value of $<$ 0.05 was considered statistically significant. Regression analysis with a linear model was used to analyze the correlation between continuous parameters. Statistical analysis was performed using IBM SPSS Statistics for Windows, Version 22.0 (Armonk, NY).

\section{Results}

We enrolled a total of 73 patients with chest pain. The STEMI group included 56 patients who underwent a primary PCI for total coronary occlusion. The control group included 17 subjects who presented with chest pain but had patent coronary arteries. In the control group, two patients visited the emergency department due to aggravating typical angina, 14 patients had stressinduced ischemia in thallium myocardial perfusion imaging, and one patient had progressive chest pain despite optimal medical treatment for reflux esophagitis; 11 patients were diagnosed as syndrome $\mathrm{X}$, two patients had myocardial bridge, one patient had apical hypertrophy, one patient had coronary spasm, one patient had reflux esophagitis, and one patient had atrial fibrillation with rapid ventricular response. The demographic profile of study subjects is shown in Table 1 . There was no difference in age, gender, or atherosclerosis risk factors such as hypertension, diabetes, dyslipidemia, and smoking between the two groups, as well as no differences in serum LDL and hemoglobin A1c. Two patients in the STEMI group died from cardiogenic shock; one had diabetes with multivessel coronary lesions. Among the 54 STEMI survivals, 12 were diabetes; 5 out of these 12 diabetic STEMI patients had multivessel lesions. None of our study subjects was on regular B-vitamin supplements for more than 1 year before enrollment.
White blood cell (WBC) counts $\left(11.9 \pm 4 \times 10^{9}\right.$ vs. 6.5 $\left.\pm 2 \times 10^{9} / \mathrm{L}, p<0.001\right)$, CRP $(2.0 \pm 3.0$ vs. $0.2 \pm 0.1 \mathrm{mg} / \mathrm{L}$, $p<0.001)$, serum creatinine levels $(1.2 \pm 0.8$ vs. $0.9 \pm$ $0.2 \mathrm{mg} / \mathrm{dL}, p=0.004)$, and QTc $(441.1 \pm 48$ vs. $416.6 \pm$ $21 \mathrm{~ms}, p=0.044)$ were higher in STEMI patients. The LVEF was lower in the STEMI group $(54.1 \% \pm 12 \%$ vs. $69.6 \% \pm 6 \%, p<0.001$ ) (Table 2). There was no significant difference in serum homocysteine levels $(8.4 \pm 2.2$ vs. 7.6 $\pm 1.9 \mu \mathrm{mol} / \mathrm{L}, p=0.142)$ after two outliers were excluded (Table 2). The two outliers (homocysteine of 36.8 and $32.3 \mu \mathrm{mol} / \mathrm{L}$ ) were classified as Killip I and II, respectively, without renal impairment. The average follow-up time was $19.3 \pm 1.9$ months in the STEMI group, while one of the STEMI patients died of refractory ventricular fibrillation 4 days after the event day and another of pump failure 5 days later (Table 3). There was no difference in E/E' values in echocardiographic measurements or the percentage of early repolarization shown in electrocardiograms between the two groups, while there was a trend of greater QRS fragmentation in the STEMI group $(80 \%$ vs. $53 \%, p=$ 0.055).

When stratifying STEMI patients by the Killip classification, CRP $(3.3 \pm 4.1$ vs. $1.4 \pm 2.3 \mathrm{mg} / \mathrm{L}, p=0.032)$, peak CK (3796 \pm 2163 vs. $2305 \pm 1822 \mathrm{IU} / \mathrm{L}, p=0.023)$, and SYNTAX scores $(20.4 \pm 11.1$ vs. $14.8 \pm 7.6, p=0.033)$

Table 1 Demographic data of the ST-segment elevation myocardial infarction (STEMI) and control groups

\begin{tabular}{|c|c|c|c|}
\hline & STEMI & Control & $p$ value \\
\hline Number, $n$ & 56 & 17 & NA \\
\hline Age, yr & $58.1 \pm 13$ & $57.5 \pm 11$ & 0.854 \\
\hline Male, $n(\%)$ & $43(77)$ & $11(65)$ & 0.353 \\
\hline Hypertension, $n(\%)$ & $25(45)$ & $9(53)$ & 0.589 \\
\hline Diabetes, n(\%) & $13(23)$ & $3(18)$ & 0.748 \\
\hline Dyslipidemia, n(\%) & $23(41)$ & $8(47)$ & 0.781 \\
\hline Smoking, $n(\%)$ & $33(59)$ & $6(35)$ & 0.103 \\
\hline Stroke, $n(\%)$ & $7(13)$ & $1(6)$ & 0.672 \\
\hline $\begin{array}{l}\text { Peripheral arterial } \\
\text { disease, } n(\%)\end{array}$ & $0(0)$ & $0(0)$ & NA \\
\hline $\begin{array}{l}\text { End-stage renal } \\
\text { disease, } n(\%)\end{array}$ & $1(2)$ & $0(0)$ & 1.000 \\
\hline $\begin{array}{l}\text { History of congestive } \\
\text { heart failure, } n(\%)\end{array}$ & $1(2)$ & $1(6)$ & 0.414 \\
\hline $\begin{array}{l}\text { Family history of } \\
\text { myocardial infarction, } \\
n(\%)\end{array}$ & $7(13)$ & $2(12)$ & 1.000 \\
\hline $\begin{array}{l}\text { Body-mass index, } \\
\mathrm{kg} / \mathrm{m}^{2}\end{array}$ & $25.1 \pm 4$ & $25.5 \pm 6$ & 0.835 \\
\hline Mortality, n(\%) & $2(4)$ & $0(0)$ & 1.000 \\
\hline $\begin{array}{l}\text { Regular B-vitamin } \\
\text { supplements> } 1 \text { year, } n(\%)\end{array}$ & $0(0)$ & $0(0)$ & NA \\
\hline
\end{tabular}

NA not available 
Table 2 Comparison of laboratory, electrocardiographic, and echocardiographic parameters between the ST-segment elevation myocardial infarction (STEMI) and control groups

\begin{tabular}{llll}
\hline & STEMI & Control & $p$ value \\
\hline White cell count, $\times 10^{9} / \mathrm{L}$ & $11.9 \pm 4$ & $6.5 \pm 2$ & $<0.001^{*}$ \\
Homocysteine, $\mu \mathrm{mol} / \mathrm{L}$ & $8.4 \pm 2.2$ & $7.6 \pm 1.9$ & $0.142^{\mathrm{a}}$ \\
C-reactive protein, $\mathrm{mg} / \mathrm{L}$ & $2.0 \pm 3.0$ & $0.2 \pm 0.1$ & $<0.001^{*}$ \\
Low-density lipoprotein, & $111.5 \pm 38$ & $95 \pm 27$ & 0.062 \\
$\mathrm{mg} / \mathrm{dL}$ & & & \\
Creatinine, $\mathrm{mg} / \mathrm{dL}$ & $1.2 \pm 0.8$ & $0.9 \pm 0.2$ & $0.004^{*}$ \\
Hemoglobin A1c, \% & $6.5 \pm 1.6$ & $6.1 \pm 1.6$ & 0.441 \\
$\mathrm{PR}, \mathrm{ms}$ & $171.1 \pm 43$ & $173.6 \pm 48$ & 0.853 \\
QRS, ms & $94.9 \pm 24$ & $90.1 \pm 12$ & 0.273 \\
QTc, ms & $441.1 \pm 48$ & $416.6 \pm 21$ & $0.044^{*}$ \\
QRS fragmentation, $n(\%)$ & $45(80)$ & $9(53)$ & 0.055 \\
Early repolarization, $n(\%)$ & $18(32)$ & $3(18)$ & 0.362 \\
Left ventricular ejection & $54.1 \pm 12$ & $69.6 \pm 6$ & $<0.001^{*}$ \\
fraction, \% & & & \\
E/E' & $12.4 \pm 5$ & $12.4 \pm 7$ & 0.989 \\
\hline${ }^{*} p<0.05$ \\
${ }^{a}$ After the two outliers of 36.8 and $32.3 \mu \mathrm{mol} / \mathrm{L}$ were excluded
\end{tabular}

were higher in the group with increased severity (Table 3). Serum homocysteine levels did not increase with the severity of myocardial infarction (Table 3). There was also no difference in age, time from exhibition of symptoms to hospitalization, or time elapsed to peak CK (Table 3).

When serum homocysteine levels were compared to various factors, we found that there was no correlation with WBC, CRP, or the SYNTAX score (Fig. 1a-c). In addition, the level of serum homocysteine was nearly consistent despite increases in these factors $\left(R^{2}=0.0008\right.$, 0.0003 , and 0.003 , respectively).

The clinical bystander role of homocysteine was further confirmed at the cellular level. A culture system was established using HCAECs and an MTT assay to assess cell viability in the presence of homocysteine (Fig. 2). Exposure of HCAECs to $100 \mu \mathrm{mol} / \mathrm{L}$ homocysteine for up to $48 \mathrm{~h}$ did not decrease cell viability compared with the PBS control (Fig. 2). In contrast, treatment with L5 LDL, an electronegative molecule known as a risk marker in STEMI, resulted in a time-dependent decrease in cell viability in HCAECs. Even at concentrations of > $100 \mu \mathrm{mol} / \mathrm{L}$, homocysteine still did not change cell

Table 3 Relationship between the severity of ST-segment elevation myocardial infarction (STEMI) and laboratory parameters

\begin{tabular}{|c|c|c|c|c|c|}
\hline & Killip I & Killip ॥ & Killip III & Killip IV & $p$ value \\
\hline Number, $n$ & 35 & 5 & 2 & 14 & \\
\hline Age, years & $60.0 \pm 13.5$ & $63.6 \pm 13.5$ & $57.5 \pm 12.0$ & $51.3 \pm 10.6$ & 0.141 \\
\hline Symptom to hospital, h & $4.6 \pm 5.1$ & $1.2 \pm 1.3$ & $0.5 \pm 0.7$ & $5.6 \pm 5.4$ & 0.249 \\
\hline Aborted sudden death, $n(\%)$ & 1(3) & 0 & 0 & $6(43)$ & $0.001^{*}$ \\
\hline VTNf, $n(\%)$ & $1(3)$ & 0 & 0 & $5(36)$ & $0.007^{*}$ \\
\hline $\mathrm{ECMO}, n(\%)$ & 0 & 0 & 0 & $3(21)$ & $0.023^{*}$ \\
\hline IABP, $n(\%)$ & 0 & 0 & 0 & $9(64)$ & $<0.001^{*}$ \\
\hline Follow-up time, months & $19.3 \pm 2.1$ & $18.0 \pm 1.1$ & $19.0 \pm 1.8$ & $16.9 \pm 7.3$ & 0.299 \\
\hline Mortality, $n(\%)$ & 0 & 0 & 0 & $2(15)$ & 0.082 \\
\hline \multirow[t]{2}{*}{ White cell count, $\times 10^{9} / \mathrm{L}$} & $11.44 \pm 3.5$ & $13.7 \pm 1.9$ & $13.7 \pm 6.2$ & $12.0 \pm 4.9$ & 0.577 \\
\hline & $11.7 \pm 3.4$ & & $12.2 \pm 4.9$ & & 0.704 \\
\hline \multirow[t]{2}{*}{ Homocysteine, $\mu \mathrm{mol} / \mathrm{L}$} & $9.2 \pm 5.3$ & $12.9 \pm 10.9$ & $11.0 \pm 3.7$ & $8.0 \pm 2.4$ & 0.361 \\
\hline & $9.7 \pm 6.1$ & & $8.4 \pm 2.6$ & & 0.256 \\
\hline \multirow[t]{2}{*}{ C-reactive protein, mg/L } & $1.4 \pm 2.3$ & $1.4 \pm 2.5$ & $3.6 \pm 3.9$ & $3.3 \pm 4.3$ & 0.208 \\
\hline & $1.4 \pm 2.3$ & & $3.3 \pm 4.1$ & & $0.032^{*}$ \\
\hline \multirow{2}{*}{$\begin{array}{l}\text { Low-density lipoprotein } \\
\text { Cholesterol, mg/dL }\end{array}$} & $116 \pm 38$ & $102 \pm 30$ & $127 \pm 49$ & $101 \pm 41$ & 0.574 \\
\hline & $114 \pm 37$ & & $104 \pm 41$ & & 0.434 \\
\hline \multirow[t]{2}{*}{ Peak creatine kinase (CK), IU/L } & $2100 \pm 1391$ & $3737 \pm 3604$ & $2595 \pm 2773$ & $3967 \pm 2134$ & $0.016^{*}$ \\
\hline & $2305 \pm 1822$ & & $3796 \pm 2163$ & & $0.023^{*}$ \\
\hline Time to peak CK, h & $10.4 \pm 4.6$ & $9.8 \pm 4.0$ & $6.5 \pm 5.0$ & $8.6 \pm 4.0$ & 0.460 \\
\hline \multirow[t]{2}{*}{ SYNTAX score } & $14.2 \pm 7.6$ & $19.0 \pm 6.8$ & $20.0 \pm 7.1$ & $20.46 \pm 11.7$ & 0.123 \\
\hline & $14.8 \pm 7.6$ & & $20.4 \pm 11.1$ & & $0.033^{*}$ \\
\hline
\end{tabular}



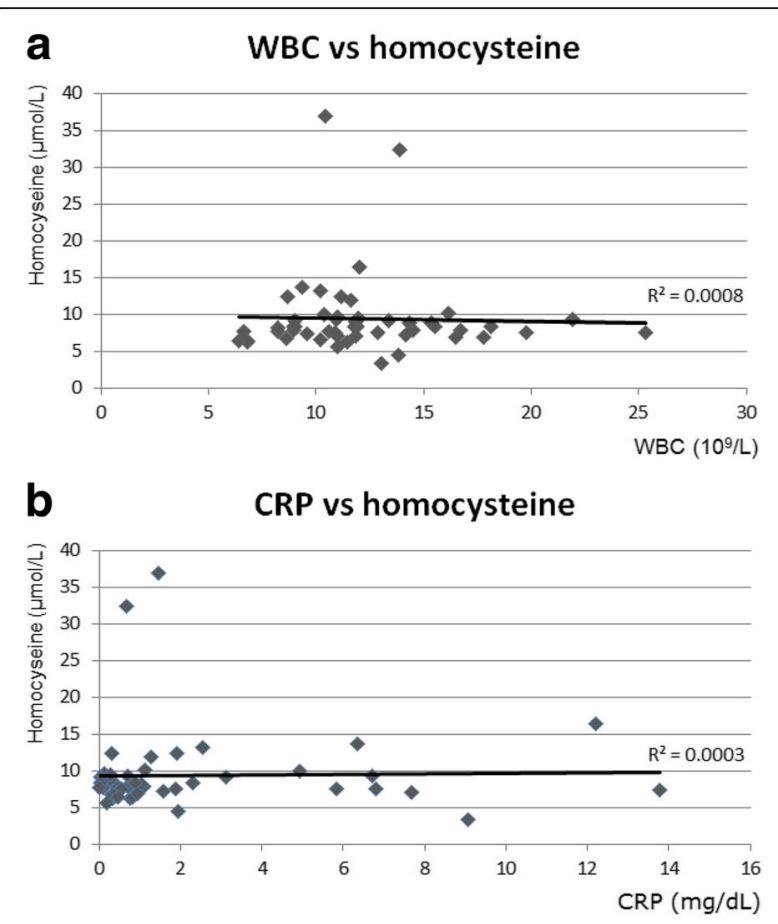

\section{SYNTAX score vs Homocysteine}

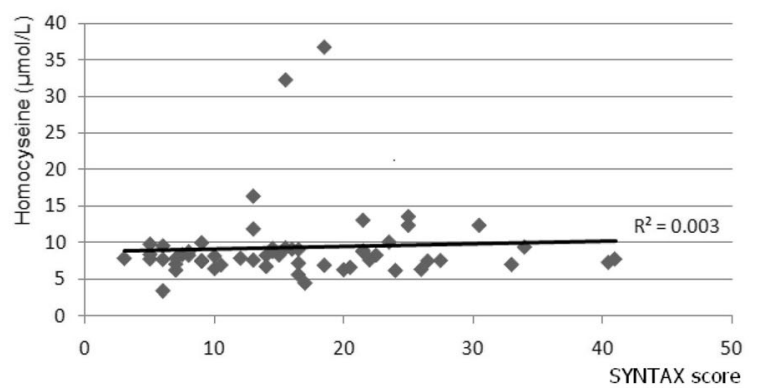

Fig. 1 Relationship between homocysteine and three independent variables in ST-elevation myocardial infarction (STEMI) patients. a White blood cells (WBCs); b C-reactive protein (CRP); c SYNTAX score

viability (data not shown). This bench evidence along with clinical observations in STEMI suggests that homocysteine is a bystander and not a causative factor of atherogenesis.

\section{Discussion}

Our study clearly demonstrated that homocysteine was not elevated in STEMI patients, and therefore, this longconsidered risk factor for $\mathrm{CAD}$ was more likely a bystander rather than a causative agent in STEMI. We believe our data are trustworthy because every study subject was evaluated in detail by coronary angiography. Our control group consisted of patients with the final diagnosis of Syndrome X, myocardial bridge [28], apical hypertrophy, coronary spasm, reflux esophagitis and atrial fibrillation, whose coronary patency was confirmed by coronary arteriography. This grouping contrasts with that reported in other studies in which "healthy" controls were based solely on non-invasive studies.

Although recent studies did not support the role of homocysteine as a risk factor in CVDs as previously thought, some reports have revealed an increase in homocysteine levels in CAD. A meta-analysis in 2002 reported that the mean serum homocysteine level in healthy populations at an average age of 56 years old was $11.8 \mu \mathrm{mol} / \mathrm{L}$, and the odds ratio for ischemic heart disease associated with a $25 \%$ lower baseline homocysteine level was 0.83 (95\% confidence interval (CI), 0.77 0.89) in prospective studies [8]. Akyurek et al. disclosed a higher serum homocysteine level in a STEMI group than in a healthy control group $(19.0 \pm 3.6$ vs. $15.8 \pm$ $4.2 \mu \mathrm{mol} / \mathrm{L}, p=0.008)$ [10]. Liu $\mathrm{C}$ et al. found that the prevalence of hyperhomocysteinemia (> $15 \mu \mathrm{mol} / \mathrm{L})$ was higher among patients with ischemic heart disease than among controls (79.1\% vs. 5\%) [29], and the serum homocysteine level was positively correlated with severity (acute myocardial infarction $23.44 \pm 5.78 \mu \mathrm{mol} / \mathrm{L}$, unstable angina $22.62 \pm 6.37 \mu \mathrm{mol} / \mathrm{L}$, stable angina $18.63 \pm$ $6.73 \mu \mathrm{mol} / \mathrm{L}$, and control $10.81 \pm 4.62 \mu \mathrm{mol} / \mathrm{L}, p<0.001$ ) [30]. In contrast, our study showed that there was no difference in serum homocysteine levels between the control and STEMI groups, and our cohort had a mean level of homocysteine markedly lower than the levels reported in previous studies. Several public health studies have also shown a great diversity among serum homocysteine levels in different countries, ranging from $6.57 \mu \mathrm{mol} / \mathrm{L}$ in Kuwait [31] to $14 \mu \mathrm{mol} / \mathrm{L}$ in Italy [32], and folic acid fortification of grain products has already decreased the prevalence of high homocysteine levels (> $13 \mu \mathrm{mol} / \mathrm{L}$ ) from $29.8 \%$ to $18.7 \%$ [33]. The variation in homocysteine levels may be attributed to ethnicity, socioeconomics, and nutritional status. Moreover, several studies demonstrating a neutral effect of homocysteinelowering therapy in acute coronary syndrome have reported mean serum homocysteine levels of approximately $10 \mu \mathrm{mol} / \mathrm{L}[16,34]$, relatively lower than those of previous studies, implying that the role of homocysteine in atherothrombotic heart disease may vary among populations with different average homocysteine levels. A trend of decreasing homocysteine levels in the general population also complicates the interaction of homocysteine and other established risk factors such as diabetes and smoking.

A previous study addressing the relationship of serum homocysteine levels with outcomes in patients with acute coronary syndrome showed that an elevated level on admission strongly predicted late cardiac events [12]. However, the rate of revascularization was $26.4 \%$ in that study, with an event rate of $9.3 \%$ over 28 days, which greatly differed from the current situation of acute 


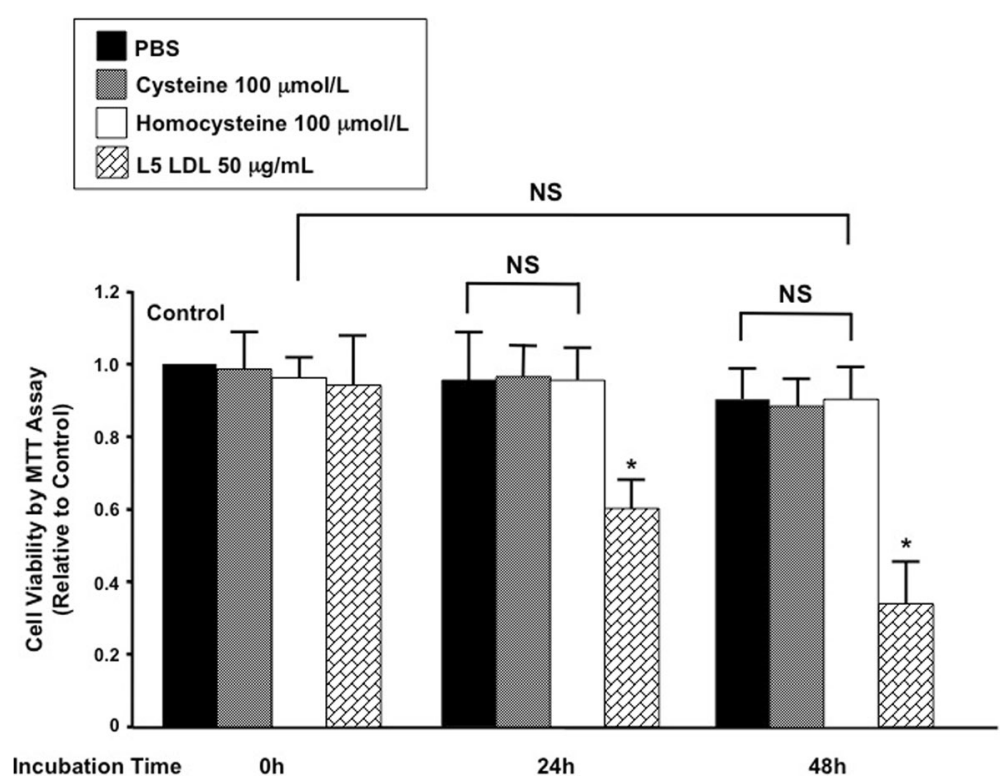

Fig. 2 Effects of homocysteine on cell viability in cultured human coronary artery endothelial cells (HCAECs). Cells were treated with the PBS control, $100 \mu \mathrm{mol} / \mathrm{L}$ cysteine, $100 \mu \mathrm{mol} / \mathrm{L}$ homocysteine, or $50 \mu \mathrm{g} / \mathrm{mL}$ L5 low-density lipoprotein (LDL) for 0, 24, and $48 \mathrm{~h}$ as indicated, and cell viability was assessed by an MTT assay. Values are the mean \pm SEM $(n=3) .{ }^{*} p<0.05$ vs. the PBS control (the first black column). NS, not significant

coronary occlusion rapidly being treated through a percutaneous intervention. Because PCI has been demonstrated to be an indispensable strategy in acute coronary syndrome, the results of the abovementioned study with low revascularization rate cannot be applied to the era of aggressive and effective revascularization. Together with the findings gathered in our study, this result implies that advances in primary PCI in STEMI and the application of new-generation drug-eluting stents as well as newer P2Y12 inhibitors may attenuate the effect of serum homocysteine on cardiovascular outcomes.

One interesting finding of our study was the elevated leukocyte count in STEMI patients. It is well known that WBC counts are elevated in subjects with acute coronary syndrome [35], and leukocytosis is a predictor of major adverse cardiac events in patients with acute coronary syndrome [36, 37]. CRP is also a risk factor for cardiovascular events with a risk ratio of 1.67 (95\% CI: $1.21 \sim 6.41)$ according to a meta-analysis of 42 prospective studies, [38] and it is an independent predictor of 30-day mortality in STEMI patients [39]. In our cohort, we observed significant increases in WBC and CRP levels in STEMI patients compared with the control group, and STEMI patients at higher Killip classes (III and IV) also had higher serum levels of these markers. However, the serum homocysteine level was consistently low regardless of the Killip class and had no correlation with WBC or CRP levels in STEMI patients. The discrepancy between our results and homocysteine's role as a cardiovascular risk factor reported in previous studies requires a thorough reevaluation of homocysteine in the development of coronary heart disease and its prognostic value in patients with myocardial infarction.

STEMI patients had higher hemoglobin A1c levels than the control group in this prospective study, although the difference was not statistically significant. Diabetes has been known as a critical predictor of STEMI outcome. Indeed, our study showed that the diabetes\% in the STEMI mortality subgroup (50\%, 1 diabetes out of 2 mortality) was much higher than that in the STEMI survivals $(21 \%, 12$ diabetes out of 54 survivals). Recent studies showed that hyperglycemic stress during acute myocardial infarction (AMI) had a negative prognostic effect, [40] and diabetic patients with incretin-based therapy had a significant lower rate of allcause mortality, cardiac death and readmission at 12 months [41]. Moreover, hyperglycemic patients with STEMI had fewer endothelial progenitor cells (EPCs) than normoglycemic patients, and an intensive glycemic control (80-140 mg/dL) group had a higher EPC number and the ability to differentiate and proportion salvaged myocardium, measured by technetium- $99 \mathrm{~m}$ sestamibi scintigraphy [42]. These studies demonstrated that metabolic factors may directly affect the outcome of AMI and the viability of EPCs, and the latter may be a proxy for the probability of myocardial salvage.

Our in vitro experiments confirmed the bystander role of homocysteine in coronary artery cell damage (Fig. 2). As a long-considered risk factor for atherosclerosis, homocysteine can exhibit synergistic EC toxicity with modified LDL by a shared pathway related to fibroblast growth factor (FGF)-2 [26]. However, the homocysteine 
concentrations used in most experiments have been much higher than the physiological level, which is < $10 \mu \mathrm{mol} / \mathrm{L}$, even under conditions with impaired folate metabolism [2]. In our study, under a supraphysiological concentration of $100 \mu \mathrm{mol} / \mathrm{L}$, homocysteine still had no detrimental effects on HCAEC viability compared with its benign structural analog, cysteine. These results indicate that homocysteine is not the culprit molecule but instead a bystander in causing endothelial injury during cardiovascular events that arise from acute plaque rupture but not de novo thrombosis. Our findings have complicated the existing notions of the relationship between homocysteine and thrombosis [43] and may explain why homocysteine-lowering therapy has failed to reduce the risk of cardiovascular events. These observations offer a potential explanation for the negative results obtained from most clinical outcome trials on homocysteine reduction and raise a new topic of future homocysteine research.

\section{Conclusions}

Unlike the leukocyte count and CRP, homocysteine was not elevated in STEMI patients regardless of Killip severity, suggesting that homocysteine is a bystander instead of a causative factor of STEMI. Our study therefore supports the current notion that homocysteine-lowering strategies are not essential in CVD prevention. Larger prospective studies are warranted to reevaluate the role of homocysteine in CAD.

\begin{abstract}
Abbreviations
CAD: Coronary artery disease; CRP: C-reactive protein; CVD: Cardiovascular disease; ECMO: Extracorporeal membranous oxygenation; IABP: Intra-aortic balloon pump; LDL: Low-density lipoprotein; LVEF: Left ventricular ejection fraction; PCI: Percutaneous coronary intervention; STEMI: ST-segment elevation myocardial infarction; WBC: White blood cell
\end{abstract}

\section{Acknowledgements}

Not applicable

\section{Funding}

This study was supported by grant NSC101-2320-B-002-026 from the National Science Council, Taipei, Taiwan (to Dr. Chang).

\section{Availability of data and materials}

Data are available on request due to privacy or other restrictions.

\section{Authors' contributions \\ CYC analyzed and interpreted the patient data and wrote the manuscript TCY performed the cell experiments. CC assisted in cell experiments. SCL analyzed the results of cell and biochemical assays. PYC coordinated the basic and clinical study and wrote the manuscript. All authors read and approved the final manuscript}

\section{Ethics approval and consent to participate}

This study was approved by the institutional review board (National Taiwan University Hospital Research Ethics Committee) with approval number NTUHREC No. 201112123RIC, and all participants provided written informed consent.

\section{Consent for publication}

Not applicable.

\section{Competing interests}

The authors declare that they have no competing interests.

\section{Publisher's Note}

Springer Nature remains neutral with regard to jurisdictional claims in published maps and institutional affiliations.

\section{Author details}

${ }^{1}$ Cardiovascular Center and Division of Cardiology, Department of Internal Medicine, National Taiwan University Hospital, 7 Chung-Shan South Road, 100 Taipei, Taiwan. ${ }^{2}$ Division of Cardiology, Department of Internal Medicine, National Taiwan University College of Medicine, No.1, Ren-Ai Road Section 1, 100 Taipei, Taiwan. ${ }^{3}$ Department of Biochemistry and Molecular Biology, National Taiwan University College of Medicine, No.1, Ren-Ai Road Section 1, 100 Taipei, Taiwan. ${ }^{4}$ Taipei American School, 800 Chung Shan North Road Section 6, Taipei 11152, Taiwan.

Received: 26 November 2017 Accepted: 7 February 2018

Published online: 13 February 2018

\section{References}

1. Mangoni AA, Jackson SH. Homocysteine and cardiovascular disease: current evidence and future prospects. Am J Med. 2002;112:556-65.

2. Crider KS, Zhu JH, Hao L, Yang QH, Yang TP, Gindler J, Maneval DR, Quinlivan EP, Li Z, Bailey LB, Berry RJ. MTHFR 677C->T genotype is associated with folate and homocysteine concentrations in a large, population-based, double-blind trial of folic acid supplementation. Am J Clin Nutr. 2011;93:1365-72.

3. De Bree A, Verschuren WM, Kromhout D, Kluijtmans LA, Blom HJ. Homocysteine determinants and the evidence to what extent homocysteine determines the risk of coronary heart disease. Pharmacol Rev. 2002;54:599-618.

4. Werstuck GH, Lentz SR, Dayal S, Hossain GS, Sood SK, Shi YY, Zhou J, Maeda N, Krisans SK, Malinow MR, Austin RC. Homocysteine-induced endoplasmic reticulum stress causes dysregulation of the cholesterol and triglyceride biosynthetic pathways. J Clin Invest. 2001;107:1263-73.

5. Wald DS, Law M, Morris JK. Homocysteine and cardiovascular disease: evidence on causality from a meta-analysis. BMJ. 2002;325:1202.

6. Moller J, Nielsen GM, Tvedegaard KC, Andersen NT, Jorgensen PE. A metaanalysis of cerebrovascular disease and hyperhomocysteinaemia. Scand J Clin Lab Invest. 2000;60:491-9.

7. Bautista LE, Arenas IA, Penuela A, Martinez LX. Total plasma homocysteine level and risk of cardiovascular disease: a meta-analysis of prospective cohort studies. J Clin Epidemiol. 2002:55:882-7.

8. Choe S. Potassium channel structures. Nat Rev Neurosci. 2002;3:115-21.

9. Verhoef P, Stampfer MJ, Buring JE, Gaziano JM, Allen RH, Stabler SP, Reynolds RD, Kok FJ, Hennekens CH, Willett WC. Homocysteine metabolism and risk of myocardial infarction: relation with vitamins B6, B12, and folate. Am J Epidemiol. 1996;143:845-59.

10. Akyurek O, Akbal E, Gunes F. Increase in the risk of ST elevation myocardial infarction is associated with homocysteine level. Arch Med Res. 2014;45:501-6.

11. Anderson JL, Muhlestein JB, Horne BD, Carlquist JF, Bair TL, Madsen TE, Pearson RR. Plasma homocysteine predicts mortality independently of traditional risk factors and C-reactive protein in patients with angiographically defined coronary artery disease. Circulation. 2000;102:1227-32.

12. Stubbs PJ, Al-Obaidi MK, Conroy RM, Collinson PO, Graham IM, Noble IM. Effect of plasma homocysteine concentration on early and late events in patients with acute coronary syndromes. Circulation. 2000:102:605-10.

13. Toole JF, Malinow MR, Chambless LE, Spence JD, Pettigrew LC, Howard VJ, Sides EG, Wang CH, Stampfer M. Lowering homocysteine in patients with ischemic stroke to prevent recurrent stroke, myocardial infarction, and death: the vitamin intervention for stroke prevention (VISP) randomized controlled trial. JAMA. 2004;291:565-75.

14. Albert CM, Cook NR, Gaziano JM, Zaharris E, MacFadyen J, Danielson E, Buring JE, Manson JE. Effect of folic acid and B vitamins on risk of cardiovascular events and total mortality among women at high risk for cardiovascular disease: a randomized trial. JAMA. 2008:299:2027-36.

15. Armitage JM, Bowman L, Clarke RJ, Wallendszus K, Bulbulia R, Rahimi K, Haynes R, Parish S, Sleight P, Peto R, Collins R. Effects of homocysteinelowering with folic acid plus vitamin B12 vs placebo on mortality and major 
morbidity in myocardial infarction survivors: a randomized trial. JAMA. 2010; 303:2486-94.

16. Ebbing M, Bleie $\mathrm{O}$, Ueland PM, Nordrehaug JE, Nilsen DW, Vollset SE, Refsum H, Pedersen EK, Nygard O. Mortality and cardiovascular events in patients treated with homocysteine-lowering B vitamins after coronary angiography: a randomized controlled trial. JAMA. 2008;300:795-804.

17. Lonn E, Held C, Arnold JM, Probstfield J, McQueen M, Micks M, Pogue J, Sheridan P, Bosch J, Genest J, Yusuf S. Rationale, design and baseline characteristics of a large, simple, randomized trial of combined folic acid and vitamins B6 and B12 in high-risk patients: the heart outcomes prevention evaluation (HOPE)-2 trial. Can J Cardiol. 2006;22:47-53.

18. Foussas SG, Zairis MN, Makrygiannis SS, Manousakis SJ, Patsourakos NG, Adamopoulou EN, Beldekos DJ, Melidonis Al, Handanis SM, Manolis AJ, et al. The impact of circulating total homocysteine levels on long-term cardiovascular mortality in patients with acute coronary syndromes. Int J Cardiol. 2008;124:312-8.

19. Palmerini T, Biondi-Zoccai G, Della Riva D, Mariani A, Sabate M, Smits PC Kaiser C, D'Ascenzo F, Frati G, Mancone M, et al. Clinical outcomes with bioabsorbable polymer- versus durable polymer-based drug-eluting and bare-metal stents: evidence from a comprehensive network meta-analysis. J Am Coll Cardiol. 2014;63:299-307.

20. D'Ascenzo F, lannaccone M, Saint-Hilary G, Bertaina M, Schulz-Schupke S, Wahn Lee C, Chieffo A, Helft G, Gili S, Barbero U, et al. Impact of design of coronary stents and length of dual antiplatelet therapies on ischaemic and bleeding events: a network meta-analysis of 64 randomized controlled trials and 102735 patients. Eur Heart J. 2017;38:3160-72

21. Andell P, James SK, Cannon CP, Cyr DD, Himmelmann A, Husted S, Keltai M, Koul S, Santoso A, Steg PG, et al. Ticagrelor versus Clopidogrel in patients with acute coronary syndromes and chronic obstructive pulmonary disease: an analysis from the platelet inhibition and patient outcomes (PLATO) trial. J Am Heart Assoc. 2015;4:e002490.

22. Wiviott SD, Braunwald E, McCabe CH, Montalescot G, Ruzyllo W, Gottlieb S, Neumann FJ, Ardissino D, De Servi S, Murphy SA, et al. Prasugrel versus clopidogrel in patients with acute coronary syndromes. N Engl J Med. 2007; 357:2001-15.

23. O'Gara PT, Kushner FG, Ascheim DD, Casey DE Jr, Chung MK, de Lemos JA, Ettinger SM, Fang JC, Fesmire FM, Franklin BA, et al. ACCF/AHA guideline for the management of ST-elevation myocardial infarction: a report of the American College of Cardiology Foundation/American Heart Association task force on practice guidelines. Circulation. 2013;2013(127):e362-425.

24. Ibanez B, James S, Agewall S, Antunes MJ, Bucciarelli-Ducci C, Bueno H, Caforio ALP, Crea F, Goudevenos JA, Halvorsen S, et al. ESC guidelines for the management of acute myocardial infarction in patients presenting with ST-segment elevation: the task force for the management of acute myocardial infarction in patients presenting with ST-segment elevation of the European Society of Cardiology (ESC). Eur Heart J. 2017;2018(39):119-77.

25. Chang PY, Chen YJ, Chang FH, Lu J, Huang WH, Yang TC, Lee YT, Chang SF, Lu SC, Chen CH. Aspirin protects human coronary artery endothelial cells against atherogenic electronegative LDL via an epigenetic mechanism: a novel cytoprotective role of aspirin in acute myocardial infarction. Cardiovasc Res. 2013;99:137-45.

26. Chang PY, Lu SC, Lee CM, Chen YJ, Dugan TA, Huang WH, Chang SF, Liao WS, Chen CH, Lee YT. Homocysteine inhibits arterial endothelial cell growth through transcriptional downregulation of fibroblast growth factor-2 involving G protein and DNA methylation. Circ Res. 2008;102:933-41.

27. Chang PY, Luo S, Jiang T, Lee YT, Lu SC, Henry PD, Chen CH. Oxidized low-density lipoprotein downregulates endothelial basic fibroblast growth factor through a pertussis toxin-sensitive G-protein pathway: mediator role of platelet-activating factor-like phospholipids. Circulation. 2001;104:588-93.

28. Cerrato E, Barbero U, D'Ascenzo F, Taha S, Biondi-Zoccai G, Omede P, Bianco M, Echavarria-Pinto M, Escaned J, Gaita F, Varbella F. What is the optimal treatment for symptomatic patients with isolated coronary myocardial bridge? A systematic review and pooled analysis. J Cardiovasc Med (Hagerstown). 2017;18:758-70.

29. Liu C, Yang Y, Peng D, Chen L, Luo J. Hyperhomocysteinemia as a metabolic disorder parameter is independently associated with the severity of coronary heart disease. Saudi Med J. 2015;36:839-46.

30. Ma Y, Peng D, Liu C, Huang C, Luo J. Serum high concentrations of homocysteine and low levels of folic acid and vitamin B12 are significantly correlated with the categories of coronary artery diseases. BMC Cardiovasc Disord. 2017:17:37.

31. Akanji AO, Thalib L, Al-Isa AN. Folate, vitamin B(1)(2) and total homocysteine levels in Arab adolescent subjects: reference ranges and potential determinants. Nutr Metab Cardiovasc Dis. 2012;22:900-6.

32. Zappacosta B, Persichilli S, lacoviello L, Di Castelnuovo A, Graziano M, Gervasoni J, Leoncini E, Cimino G, Mastroiacovo P. Folate, vitamin B12 and homocysteine status in an Italian blood donor population. Nutr Metab Cardiovasc Dis. 2013;23:473-80

33. Jacques PF, Selhub J, Bostom AG, Wilson PW, Rosenberg $\mathbb{H}$. The effect of folic acid fortification on plasma folate and total homocysteine concentrations. N Engl J Med. 1999;340:1449-54.

34. Doshi SN, McDowell IF, Moat SJ, Payne N, Durrant HJ, Lewis MJ, Goodfellow $J$. Folic acid improves endothelial function in coronary artery disease via mechanisms largely independent of homocysteine lowering. Circulation 2002;105:22-6.

35. Takeda Y, Suzuki S, Fukutomi T, Kondo H, Sugiura M, Suzumura H, Murasaki G, Okutani H, Itoh M. Elevated white blood cell count as a risk factor of coronary artery disease: inconsistency between forms of the disease. Jpn Heart J. 2003:44:201-11.

36. Hatmi ZN, Saeid AK, Broumand MA, Khoshkar SN, Danesh ZF. Multiple inflammatory prognostic factors in acute coronary syndromes: a prospective inception cohort study. Acta Med Iran. 2010;48:51-7.

37. Cabrerizo García SJL, Zalba EB, Pérez CJI, Ruiz RF. Leukocyte count as a risk factor for coronary adverse events among patients admitted for an acute coronary syndrome. Rev Med Chil. 2010;138:274-80.

38. Barbero U, D'Ascenzo F, Nijhoff F, Moretti C, Biondi-Zoccai G, Mennuni M, Capodanno D, Lococo M, Lipinski MJ, Gaita F. Assessing risk in patients with stable coronary disease: when should we intensify care and follow-up? Results from a meta-analysis of observational studies of the COURAGE and FAME era. Scientifica (Cairo). 2016:2016:3769152.

39. Ribeiro DR, Ramos AM, Vieira PL, Menti E, Bordin OL Jr, Souza PA, Quadros AS, Portal VL. High-sensitivity C-reactive protein as a predictor of cardiovascular events after ST-elevation myocardial infarction. Arq Bras Cardiol. 2014;103:69-75.

40. Marfella R, Sardu C, Balestrieri ML, Siniscalchi M, Minicucci F, Signoriello G, Calabro P, Mauro C, Pieretti G, Coppola A, et al. Effects of incretin treatment on cardiovascular outcomes in diabetic STEMI-patients with culprit obstructive and multivessel non obstructive-coronary-stenosis. Diabetol Metab Syndr. 2018;10:1.

41. Marfella R, Sardu C, Calabro P, Siniscalchi M, Minicucci F, Signoriello G, Balestrieri ML, Mauro C, Rizzo MR, Paolisso G, Barbieri M. Non-ST-elevation myocardial infarction outcomes in patients with type 2 diabetes with nonobstructive coronary artery stenosis: effects of incretin treatment. Diabetes Obes Metab. 2017. https://doi.org/10.1111/dom.13122. [Epub ahead of print].

42. Marfella R, Rizzo MR, Siniscalchi M, Paolisso P, Barbieri M, Sardu C, Savinelli A, Angelico N, Del Gaudio S, Esposito N, et al. Peri-procedural tight glycemic control during early percutaneous coronary intervention up-regulates endothelial progenitor cell level and differentiation during acute ST-elevation myocardial infarction: effects on myocardial salvage. Int J Cardiol. 2013;168:3954-62.

43. Undas A, Brozek J, Szczeklik A. Homocysteine and thrombosis: from basic science to clinical evidence. Thromb Haemost. 2005;94:907-15.

\section{Submit your next manuscript to BioMed Central and we will help you at every step:}

- We accept pre-submission inquiries

- Our selector tool helps you to find the most relevant journal

- We provide round the clock customer support

- Convenient online submission

- Thorough peer review

- Inclusion in PubMed and all major indexing services

- Maximum visibility for your research

Submit your manuscript at www.biomedcentral.com/submit 